\title{
Longing for Independence, Yet Depending on Family Support: A Qualitative Analysis of Psychosocial Adaptation of Iranian International Students in Hungary
}

\author{
Sara Hosseini-Nezhad ${ }^{1}$, Saba Safdar ${ }^{2} \&$ Lan Anh Nguyen Luu ${ }^{3}$ \\ ${ }^{1}$ Doctoral School of Psychology, Faculty of Education and Psychology, Eötvös Loránd University (ELTE), Budapest, \\ Hungary \\ ${ }^{2}$ University of Guelph, Ontario, Canada \\ ${ }^{3}$ Faculty of Education and Psychology, Eötvös Loránd University (ELTE), Budapest, Hungary \\ Correspondence: Sara Hosseini-Nezhad, Doctoral School of Psychology, Faculty of Education and Psychology, \\ Eötvös Loránd University (ELTE), Budapest, Hungary. E-mail: sara_hosseininezhad@yahoo.com
}

Received: July 3, 2019

Accepted: July 24, 2019

Online Published: July 25, 2019

doi:10.5430/ijhe.v8n4p164

URL: https://doi.org/10.5430/ijhe.v8n4p164

\begin{abstract}
International students experience psychosocial changes in response to their new environment, and their psychosocial adaptation is facilitated or hindered by various factors. This study aimed to examine the intercultural experiences of Iranian international students in Hungary. In-depth interviews were conducted with 20 Iranian students in Budapest, Hungary, and a thematic analysis employed to discern and interpret themes within the data. The thematic analysis identified three overarching themes: (1) Sojourn's Experience as Self-Growth, (2) Uncertainty in Intercultural Interactions, and (3) Striving for Autonomous-Related Self. The data reported that Iranian students experienced more happiness in Hungary than sadness, and their motivation to live independently in Hungary while depending on family support acted as buffers against any negative psychological feelings. The findings of this study underline the significance of independence and family support as the influencing factors for psychosocial adaptation of Iranian students.
\end{abstract}

Keywords: Iranian international student, psychosocial adaptation, independent, family, autonomous-related self

\section{Introduction}

The number of international students who are studying outside their country of origin has been rapidly increasing over the past decades (Organisation for Economic Co-operation and Development [OECD], 2014). Among central European countries, Hungary has become a popular study-abroad destination for international students (European Migration Network [EMN], 2012). According to Hungarian Equivalence and Information Centre (Oktatási Hivatal, 2017-2018), out of 167 countries, the top five sending countries of international students to Hungary are Germany, Romania, China, Serbia, and Iran. Iranian international students rank number fifth $(\mathrm{n}=1,878)$, and they make up six percent of all the international students in Hungary. An examination of the psychosocial adaptation of this group is the focus of the current study.

\subsection{Background and Related Literature}

\subsubsection{Cross-Cultural Adaptation}

In cross-cultural literature, the investigation of acculturation and its outcome, cross-cultural adaptation, has been the center of interest for many researchers (e.g., Brisset, Safdar, Lewis, \& Sabatier, 2010; Gui, Safdar, \& Berry, 2016). Acculturation occurs when groups of people with different cultures come into ongoing direct contact with each other that results in the cultural and psychological changes of either or both groups (Berry, 1997). Two main ways that cross-cultural adaptation has been examined are psychological adaptation and socio-cultural adaptation. Psychological adaptation is related to psychological health and life satisfaction, while socio-cultural adaptation is related to the capability of fitting into a new society and gaining cultural skills in order to interact with the host society (Ward \& Kennedy, 1999). 
It has been reported that international students experience a range of psychological difficulties including loneliness, anxiety, and stress all of which have negative impacts on their psychological adaptation (Brisset, Safdar, Lewis, \& Sabatier, 2010; Ward \& Kennedy, 1999). Similarly, it has been found that factors such as time spent in the host society, the extent of interaction with the host residents, cultural distance, language proficiency, and acculturation strategies influence the socio-cultural adaptation of international students (Gui, Safdar, \& Berry, 2016; Ward \& Kennedy, 1999). Successful adaptation and positive well-being have been found to be related to language proficiency, previous intercultural experiences, the presence of social networks, knowledge of the host culture, lack of perception of discrimination at the university (Hartshorne \& Baucom, 2007; Markova, 2006), and satisfaction of autonomy and relatedness needs (Vansteenkiste, Lens, Soenens, \& Luyckx, 2006).

According to Kagitcibasi (2007), the psychological health and adaptation of immigrant children are enhanced when the development of the autonomous-related self is nourished. It is argued that autonomous-related self is adaptive when autonomy is demanded by society, and additionally, it is profiting by the mental help given by close connections (Kagitcibasi, 2007). In a study conducted with university students from Turkey, the United States, Hong Kong, and Sweden, students admitted that an individual could be autonomous and have a close bond with someone at the same time (Kagitcibasi, 2005, 2007).

Studies on Iranian international students are limited, and there is no study on this group in Hungary. Several studies are conducted on Iranian students in Scotland (Mehdizadeh \& Scott, 2005), Russia (Baklashova \& Kazakov, 2016; and Kunovski \& Novoselova, 2018), and Malaysia (Shahmohammadi, 2014; Falavarjani \& Yeh, 2017; Nabavi \& Bijandi, 2018). There is no study that has been conducted on Iranian students in Eastern and Central Europe. Furthermore, to our knowledge, until now, no research has been conducted on Iranian students in Hungary.

\subsection{Research Aim}

The purpose of this qualitative study was to investigate the intercultural experiences of Iranian international students in Hungary and the factors that influenced their experiences. Thematic analysis (Braun \& Clarke, 2006) was utilized to identify the main themes associated with a psychosocial adaptation which have become the focus of this study.

\section{Methods}

The research design adopted an inductive approach for qualitative data analysis that was carried out through semi-structured in-depth interviews to elicit the intercultural experiences of Iranian students in Hungary, which were significant to their cross-cultural adaptation. Thematic analysis was deemed as the most appropriate method of analysis as the focus of the study was to identify themes within the participants' perspective on their intercultural experiences in Hungary.

\subsection{Ethics}

Permission to conduct this research was granted by the Research Ethics Committee of the Faculty of Education and Psychology at the Eötvös Loránd University (ELTE) in Budapest, Hungary.

\subsection{Participants}

Participants were recruited over the course of five months between October 2017 and February 2018. Twenty Iranian international undergraduate and graduate students (13 males, 65\% and 7 females, 35\%) in Budapest, Hungary participated in the semi-structured, in-depth interviews. Participants were aged 18 to 36 with the mean age of 25.8 $(\mathrm{SD}=5.59)$ and were all studying in English. The inclusion criteria for this research were Iranian undergraduate and graduate students in Hungary aged over 18 who have lived in Hungary for at least five months. Each interview lasted approximately one to two hours and was digitally audio-recorded with the consent of the participants.

\subsection{Procedures}

Participants were mostly recruited via social media platforms, in particular, via posting an advertisement form on Facebook groups, and few were recruited through snowball sampling. The primary purpose of the study presented to the participants in the advertisement form was to explore the intercultural experiences of Iranian students in Hungary. Prior to each interview, written consent was acquired from each participant. Interviews were carried out using a semi-structured format and were primarily conducted by the first author, who is Iranian and fluent in Persian and English languages. Most participants preferred to be interviewed in Farsi (Persian), while three of them preferred English. The Farsi (Persian) interview transcripts were further translated into English via oTranscribe software by the first author. 


\subsection{Instrumentation}

\subsubsection{Demographic Questions}

The demographic data questions composed of items including age, gender, the name of the college or university, previous experiences of living abroad, marital status, study major, students' sources of financial support, language of studies, English and Hungarian language proficiency level, academic competency level, and housing information (living with co-nationals, internationals, or Hungarians).

\subsubsection{Semi-Structured Interview Questions}

Semi-structured interview questions composed of 13 topics that encouraged participants to speak freely about their living experiences in Hungary. The interview questions which were based on the literature on international students explored the push and pull factors, perceived host attitudes, cultural distance, social supports and networks, previous intercultural experiences, differences in gender role-related experiences, identity and its aspects, psychological and socio-cultural adaptation, acculturative orientation and stressors, daily life and academic hassles, coping with hassles, resources, and appraisal of their stay in Hungary. (Note 1)

\subsection{Data Analysis}

\subsubsection{Thematic Analysis}

The interview transcripts were mainly analyzed using the six thematic analysis phases outlined by Braun and Clarke (2006).

In the first phase, the audiotape was listened to several times before doing the verbatim transcription on oTranscribe software. For the three interviews that were conducted in English, the data were directly transcribed via oTranscribe; however, for the rest of the interviews conducted in Persian, the translation and transcription of the data from Persian to English co-occurred on oTranscribe.

In the second phase, the English transcripts were coded on Atlas.ti6. First, open coding was utilized through both line-by-line and against a sentence or paragraph which generated 103 initial codes.

In the third phase, the generated codes were further classified into categories based on their similarities. In order to organize groups of codes, two methods were used: (1) Making families and (2) assigning prefixes to the codes. First families were made in "Code Family Manager" on Atlas.ti6. Following, specific prefixes, in this case, symbols (i.e., \#, @, II, §, Ç, @ $\circledR^{\circledR}$, etc.) were assigned to groups of codes (Woolf, 2007). "This draws attention to the specialized purpose or features of codes and causes them to sort together as a group in the Code Manager" (Woolf \& Silver, 2018 , p.44). After grouping and organizing the codes were complete, searching for the themes was performed. The initial codes that were created in the second stage were re-coded and refined based on their similarities and overlaps, and then these new sets of codes were combined into potential themes.

In the fourth phase, the potential themes that were extracted in the third stage were reviewed again to see if they needed further refinement, elimination, combination, and/or separation to obtain final themes. The final themes were checked based on the similarity of the extracted codes.

In the fifth stage, final themes were refined meaning that they were named and defined.

In the sixth stage, after the themes were defined and named, the final report conveyed the results of the analysis in a way that assured the validity of the result by using empirical evidence and a theoretical framework from the literature.

\section{Results}

The result of the thematic analysis generated three key themes: (1) Sojourn's experience as self-growth, (2) Uncertainty in intercultural interactions, and (3) Striving for autonomous-related self.

\subsection{Sojourn's Experience as Self-Growth}

The majority of the participants reported being generally happy in Hungary and happy in their day-to-day life. The participants stated:

"I am happy, even from the beginning. If I go back in time, probably I would choose here [...] I am satisfied." (Participant 8)

"I am both happy and unhappy at the same time. I am happy because I am independent [...] Living alone is the part that I am not happy about." (Participant 16) 
“Living alone helps self-growth, and it will be part of your personality.” (Participant 16)

"I am happy with the fact that I am in Hungary [...] I am happy with my day to day life in Hungary."

(Participant 13)

“Right now I am satisfied and happy [...] I am happy that I have come here.” (Participant 15)

"I am generally a person who tries to be happy [...] I try to keep myself happy anywhere I am [...] My family is not here with me, that is why I try to make myself happy with social media [...]." (Participant 6)

The majority of the Iranian students in Hungary stated that they are not sad about being away from Iran and family, and only a few of them reported being sad. Typical responses when asked if they were sad to be away from Iran and their families were:

“No, I am not sad.” (Participant 10)

"I am pleased with the fact that I am not in Iran." (Participant 3)

"For sure I am sad that I am away, but the things that I have here, the good feelings that I have here have been much better than being away from Iran [...]” (Participant 13)

"Here there is more freedom; I am independent [...]I feel I will grow faster [...] I only like to be in contact with an international person, to learn a new culture [...] I have studied in English. It has been a huge benefit, and our university is accepted in most of the European countries." (Participant 13)

Participants did not evaluate their distance from family and Iran as a depressive or an anxiety-provoking experience, perhaps because of the resources that were available to them in Hungary which helped them cope with being away from Iran and family. These resources include a chance to live independently, to have more freedom, to learn a new language and new cultures, to study in English, to get familiar with the multicultural environment, and to acquire a European degree.

The majority of participants did not experience homesickness in Hungary, and only a few reported feeling homesick. Moreover, half of the participants reported a feeling of loneliness, while the other half did not. Participants' responses stated that they did not feel homesick nor alone; however, that they did at times miss their parents:

"The feeling of homesickness [...], no. I mean because like I can go back to Iran anytime I want [...] Feeling of loneliness, yes... It's not a feeling of loneliness, but perhaps like sometimes I just miss my parents. ” (Participant 9)

"Yes, I feel homesick [...] Iranians here should go after their interests because they are coming from Iran, they are given this opportunity to go after their interest [...] It is important for them not to only focus on studying, [...] If they make their life multi-dimensional, they can easier adapt with homesickness, depression, and being away from home." (Participant 16)

\subsection{Uncertainty in Intercultural Interactions}

Half of the participants reported being nervous about how to behave in certain situations in Hungary, and the other half did not experience any anxiousness/nervousness. Typical responses included:

"A lot of times [to become nervous] [...] I think I am presenting Iranians and Iranian culture, I feel like the whole Iran depends on me [...] I try not to do anything wrong, or not to say anything bad [...]It is on my mind to watch my behavior, like don't do this, sit properly, or eat clean, stuff like these." (Participant 13)

"Yes, it happens a lot [to be nervous in certain situations] [...] I think about what I have said or what I have done when I am doing something [...] The biggest problem is that when you see people from different countries, you don't know if to shake hands, give hugs, or kiss [...] It's very problematic." (Participant 12)

"In the beginning, I had [anxiety]; now not, I don't have [anxiety]; I feel more comfortable[...]." (Participant 19)

"I have stress, like how to make myself understood, stressed about not to say a word wrong [...] I am worried what if I have made a person upset about the things that I am doing, or what if I am trying to make very close contact and make him/her feel bad." (Participant 3)

\subsection{Striving for Autonomous-Related Self}

In this study, many Iranian students embraced being independent in Hungary, and the responses included comments such as:

"You become more independent [...] because in Iran, unfortunately, the chance of living alone is very low, you are either married or living with your family [...], So when you come abroad, you become independent." (Participant 2) 
"I see myself as an independent person. Now I feel I am deciding about my thoughts, myself. Possibly I am not following my family in many situations, and I feel I'm starting a second life. Perhaps the first life is now over, and now this is the second life." (Participant 10)

"When international students come here, they have to live independently without the family; this is very beneficial for them. Because Hungarians who live with their family, keep nagging that their family is controlling them and doesn't let them go out." (Participant 12)

The oldest male participant articulated:

"In Iran [...] you are beside your family. Family supports you in many things, and you also don't even need to do your personal stuff yourself. However, outside of Iran, the positive point is that you learn how to live independently[...] You should try to handle many things, like expenses, your friendship [...] These things teach you and increase your experience for your future life." (Participant 8)

"The family will focus on you so much, and they anyhow pay attention to whom you are hanging out with; however, here you somehow decide for yourself with whom you want to spend time. This stuff increases your experiences." (Participant 8)

For many participants, the control their parents imposed on them limited their independent living and encouraged more dependency on them which prevented them from learning how to manage everyday tasks (i.e., banking and transactions, shopping, and office works, etc.). Except for a few Iranian students in this study who were either financially or psychologically independent from their family, the majority relied on their family, mostly on their parents for both financial and psychological support.

The participants noted that:

"Parents support me both financially and psychologically. I haven't had experience of living alone. When they visit me, they give me support." (Participant 16)

"When my parents visit me I definitely don't need to cook [...] When I come back home, the food is ready, this is so relaxing [...] My father does the shopping, and my mother does the cooking, so when I come home I am only busy with studying [...]" (Participant 6)

"For financial support, I turn to my father, for psychological support, I turn to my mother." (Participant 9)

"During the exam period, I talk less to my parents, but if I have to do something and I need help which is related to them, I call them almost every hour [...], but on average I contact them every two days." (Participant 13)

"My mom almost calls me once a day. If my phone is not off, then I can talk to her almost every night on Skype, almost every night." (Participant 2)

"I am very close to my family; I talk to my mother almost every day [...] University was hard [...] I was getting help from my family [...] because my parents are doctors [...] I have a good family." (Participant 20)

Although family support had beneficial effects on psychosocial adaptation and mental health of Iranian students in Hungary; in some situations the support from the family especially parents wasn't helpful since it created excessive worries in the parents.

A thirty-year-old female student stated that:

"We talk to our families a lot, because they get worried all the time [...] My mom gives me instructions [...] She tells me to close the door [...] close the window [...] I am very close to my parents [...] Parents are the only people who give you real love, period [...] Sometimes I get the feeling that I need their love [...]; however, for problems, I don't want to bother them [...] I used to bother my mom a lot on Skype and I realized that it was really affecting her [...] If I have a problem I try to solve it with my friends or one of my sisters, but I don't want to talk about problems with my parents." (Participant 2)

The youngest male participant mentioned:

"For psychological support, I honestly turn to nobody [...] I don't want to contact my family because they get too sensitive and go crazy." (Participant 5)

In general, the participants expressed that although parents may have good intentions and doubtlessly care about their children, sometimes they have difficulties in managing and setting the boundaries between themselves and their children, and they might hold on to their adult children too tightly which makes their children feel incompetent to live independently abroad. The majority of Iranian students in Hungary preferred to get help from their parents, and they 
truly trusted their parents more than they trusted their friends; however, when facing a difficulty, they chose to either solve their issues by themselves or turn to others for support.

\section{Discussion}

Using thematic analysis, this study explored the intercultural experiences of Iranian international students in Hungary and the factors that influenced their experiences. Thematic analysis identified three key themes: (1) Sojourn's experience as self-growth, (2) Uncertainty in intercultural interactions, and (3) Striving for autonomous-related self. All of the three themes were significant in understanding the psychosocial adaptation of Iranian students in Hungary. Below each of the key themes will be explored with referring to the relevant literature.

\section{Theme 1: Sojourn's Experience as Self-Growth}

Most participants' evaluation of their sojourn's experience was more positive. Participants reported being happy in Hungary, and the majority did not express sadness to be away from Iran and their family. This is consistent with previous literature on international students. In a study of Iranian international students in Australia, Nahidi, Blignault, Hayen, and Razee (2018) found that the majority of participants were not distressed. This was due to a number of protective factors, including strong social support, good physical health, and more religious engagement and spirituality, which acted as buffers against students' psychological health. In another Australian study, Rosenthal, Russell, and Thomson (2008) found that the majority of international students who were from different nationality reported positive psychological well-being (low level of depression, anxiety, and/or stress) and only a few of them perceived the experience of studying abroad profoundly damaging their mental health.

In addition to the positive feelings reported by the majority of the participants in the current study, many Iranian students believed that studying abroad led to their self-growth. This is also consistent with the result of a qualitative study conducted on international students in China and France (Cui, 2013) in which the experiences of international students and their significant effect on students' self-development were investigated. In Cui's study, many students perceived study abroad as a substantial life experience for self-acknowledgment, achieving maturity, and exploring a new place and their unknown self. They also believed they had been transformed into "independent", "tolerant", and "responsible" people as a result of moving abroad which is the "experience of self-discovery and self-development in an unfamiliar context, a process of self-realization that reinforces their confidence, challenges their limits and helps them find their potential in an international environment" (Cui, 2013, p. 472).

Many participants in the current study stated that they did not feel homesick and lonely, while at the same time, they reported that they missed their family back home. This may seem contradictory since the main characteristics of homesickness are categorized as missing family, friends, home environment, and feeling insecure and lonely (Fisher \& Hood, 1987). However, it is noteworthy to mention that to consider a person homesick, just missing family and friends per se is not enough. Homesickness is "generally represented as an intense longing for home accompanied by a depressive mood and a variety of somatic complaints" (Van Tilburg, Vingerhoets, \& Van Heck, 1996, p. 899). Furthermore, perhaps to Iranians the word "Homesickness" is more associated with being away from home, since in Persian "homesickness" literally means "missing home"; and this might be the reason why hearing the word "homesickness" did not evoke feelings of longing for a family instead it evoked feelings of longing for a home.

\section{Theme 2: Uncertainty in Intercultural Interactions}

Many Iranian students reported being anxious about how to behave in certain situations in Hungary, most likely as they lacked effective intercultural communication and intercultural adjustment due to a high level of anxiety and uncertainty. This further created doubt and fear while interacting with non-Iranians. Furthermore, some Iranian students might have felt the pressures connected to the role of a 'foreign ambassador' (Ward, Bochner, \& Furnham, 2001) when they interacted with the people in the host culture, and this, in turn, influenced their feelings of anxiousness. Participants expressed being hyper-alert of their behaviors as they perceived to be an ambassador for Iran. Arguably, their anxiety could be due to ta'arof, which is a social principle or art of social etiquette in Iranian culture defined as "a system of ceremonial politeness" (Haghighat, 2016, p.9). Many Iranians try hard to be respectful, modest, and humble toward the other people. The attempt to be the best of oneself in front of others requires efforts and energies, which, in turn, could cause stress.

Moreover, nonverbal communication is significantly different across cultures and can create cross-cultural misinterpretations (Masgoret \& Ward, 2006). Probably, many participants had problems understanding non-verbal communication due to the contradictions that existed between their cultural schemas regarding non-verbal cues and that of the host culture. This further created anxiety in them since it is challenging to learn the "heuristic knowledge that is embedded within a culture" (Masgoret \& Ward, 2006, p.63). 
It has been suggested that effective communication in the intercultural situation occurs when people manage their anxiety and uncertainty (Gudykunst, 2006). This can be better managed and reached the optimum levels by being mindful in one's communication. Some of the participants in this study expressed anxiety and uncertainty in their intercultural encounter. Many of these participants were also aware of their lack of effective communication, which in turn increased their anxiety in interacting with non-Iranians.

\section{Theme 3: Striving for Autonomous-Related Self}

Family is possibly the most distinctive attribute of Iranian culture (Javidan \& Dastmalchian, 2003) as families are responsible for their children at all phases of life, and children are expected to live with their parents until they get married (Valizadeh, Zamanzadeh, Rassouli, \& Rahkar Farshi, 2018). Yet, young Iranians are influenced by Western individualistic cultures through social media while they are also influenced by the collectivistic culture of their families (Mortazavi, 2006).

In most societies with collectivistic cultures, families are characterized by strong relatedness. In contrast, in the individualistic Western societies, autonomy is more prioritized (Kagitcibasi, 2002, 2013). Kagitcibasi (2005) developed a theory called Autonomous-Related Self with two separate dimensions called Agency and Interpersonal Distance. These dimensions make four conceptualizations of agency and self-in-relation to others. Autonomous-related self is a healthier conceptualization because autonomy and relatedness are considered two essential human needs. In Western countries with more individualistic values, autonomy is related to separation from others, while in the "Majority World" with collectivistic cultures, autonomy is related to integration with others (Kagitcibasi, 2016).

Relatedness is an attribute that makes adaptation simpler, while its absence would remarkably inhibit happiness when an individual is among a different culture. When both autonomous and relatedness needs are fulfilled, people have solid relational connections and in the meantime are independent to make a decision. Given that unfulfilled needs cause anxiety, elevated amounts of both independence and relatedness are identified with positive psychological well-being, and happiness (Merdin-Uygur \& Hesapci, 2018). Many participants in this study expressed motivation to have an autonomous and independent life.

It has been suggested that young immigrants adapt to the new ways of life and are influenced by their peers in the host society (Kagitcibasi, 2003); therefore, they are exposed and tend to adopt independent values. However, youth typically do not like to be segregated from their parents; instead, they are happy to be connected to their parents. In this way, they are aiming to have an autonomous-related self (Kagitcibasi, 2003). Many Iranian students had an intrinsic need to be autonomous, "the need to feel like a personal agent in one's environment, competence, and the need to experience a sense of control and efficacy in one's actions" (Hagger, Hardcastle, Chater, Mallett, Pal, \& Chatzisarantis, 2014, p.566).

While Iranian students were eager to live independently from their parents, they received most of the support from the family and maintained their contact with their family throughout their stay in Hungary. One study reported that Iranian students who felt homesick were more capable of adapting when they stayed in touch with parents from home (Scharp, Paxman, \& Thomas, 2016). In this study, most of the participants as young as 18, and as old as 36 received either or both financial and psychological support from their parents. Brannan, Biswas-Diener, Mohr, Mortazavi, and Stein (2013) examined the correlation between perceived social support and indicators of Subjective Well-Being among students from Iran, Jordan, and the USA. It was concluded that specifically for Iranian participants, only perceived support from their family, but not friends predicted more positive emotions and lowered negative emotions significantly.

There is no specific study found on Iranian students abroad regarding their motivation to be independent and to be connected with their family. However, in one study (Watkins, Mortazavi, \& Trofimova, 2000), the importance and satisfaction ratings of independent and interdependent self-construals among students and adults in Iran, USA, Russia, and Hong Kong were assessed. The result of the study demonstrated that Iranian students in Iran considered both independent and related-self to be more important compared to their peers from Hong Kong and Russia. Furthermore, Iranian students appraised the independent-self more substantial than the American students. It is possible that Iranian students in Hungary, similar to the Iranian students in Iran value both independence (autonomy) and interdependence (family relatedness) at the same time.

\subsection{Limitations}

This study had some methodological limitations that need to be considered. To enhance the validity of the result, and analytical reliability, further research is suggested to do double-coding, "with more than one researcher 
independently assigning pre-specified codes to the data" (Ranney et al., 2015, p.10). Furthermore, although, thematic analysis is a flexible method for data analysis, "it can be potentially paralysing the researcher trying to decide what aspects of the data to focus on" (Braun \& Clarke, 2006, p.27). Initially, more themes emerged in this study; however, to narrow the focus of the study (i.e., identifying the motivations and experiences of the participants in studying abroad), others themes had to be left out to a later time for investigation. Therefore, future research is suggested to explore other significant themes. Furthermore, longitudinal research will increase the validity of the result to see any significant changes in the psychosocial adaptation of Iranian students in Hungary.

\subsection{Implications}

Further research could implement quantitative research to explore psychosocial adaptation and the factors that facilitated or hindered the adaptation of international students. Furthermore, the result of the study can help universities and clinicians to provide counseling and therapy services in order to strengthen international students' positive feeling and reduce their negative feelings. Interventions focusing on a broad spectrum of social and physical extracurricular activities, and cultural activities which provide opportunities for international students to socialize with the host culture to effectively handle their negative feelings, are strongly recommended. Universities are also suggested to help students find paid job/internship opportunities so that students will gain more financial independence.

\section{Conclusion}

The study aimed to explore the intercultural experiences of Iranian international students in Hungary. Thematic analysis indicated that Iranian students reported more happy feelings than sad feelings in Hungary with the majority of the students did not express feelings of homesickness in Hungary. Probably, students' motivation to become independent in addition to the psychological and financial support they received from their parents acted as buffers against their negative psychological feelings, including sadness, anxiousness/nervousness, and loneliness. Many participants reported that they are ambitious, strive for independent living while they were still connected to their family.

The presence of both autonomy and relatedness are pertinent to well-being and psychosocial adaptation of international students, including Iranian students in Hungary. However, in addition to motivation for autonomy and family support, other factors could have influenced participants to experience more happy feelings than sad feelings such as socio-political freedom of Hungary relative to Iran, job opportunities, valuable university degree abroad, escaping a highly competitive entry exam to the university in Iran, escaping adverse economic situation in Iran, and exposure to new experience. Yet, for many Iranian students in Hungary, being able to take responsibility for their lives and make independent decisions while receiving psychological and financial support from their family contributed to their happiness and satisfaction in Hungary.

\section{Acknowledgments and Disclosures}

We would like to thank the Iranian international students who agreed to share their experiences openly with the researchers. We would also like to express our gratitude for the support of doctoral consortium at Eötvös Loránd University (ELTE), Hungary, Budapest. Thanks are also extended for the National Research, Development and Innovation Office (K-120433) who supported the third author.

\section{References}

Baklashova, T.A. \& Kazakov, A.V. (2016). Challenges of international students' adjustment to a higher education institution. International Journal of Environmental and Science Education, 11(8), 1821-1832. http://dx.doi.org/10.12973/ijese.2016.557a

Berry, J. W. (1997). Lead article-Immigration, acculturation, and adaptation. Applied Psychology: An International Review, 46(1), 5-34. https://doi.org/10.1111/j.1464-0597.1997.tb01087.x

Brannan, D., Biswas-Diener, R., Mohr, C. D., Mortazavi, S. \& Stein, N. (2013). Friends and family: A cross-cultural investigation of social support and subjective well-being among college students. The Journal of Positive Psychology, 8(1), 65-75. http://dx.doi.org/10.1080/17439760.2012.743573

Braun, V. \& Clarke, V. (2006). Using thematic analysis in psychology. Qualitative Research in Psychology, 3(2), 77-101. https://dx.doi.org/10.1191/1478088706qp063oa

Brisset, C., Safdar, S., Lewis, J. R. \& Sabatier, C. (2010). Psychological and sociocultural adaptation of university students in France: The case of Vietnamese international students. International Journal of Intercultural Relations, 34(4), 413-426. http://dx.doi.org/10.1016/j.ijintrel.2010.02.009 
Cui, B. (2013). Study abroad as self-development: An analysis of international students' experience in China and France. Frontiers of Education in China, 8(3), 448-477. https://doi.org/10.3868/s110-002-013-0028-8

European Migration Network (EMN). (2012). National report from Hungary on immigration of international students to the EU. Fetrieved from https://ec.europa.eu/home-affairs/sites/homeaffairs/files/what-we-do/networks/european_migration_network/rep orts/docs/emn-studies/immigration students/12a._hungary_national_report_international_students_jan2013_en_version_en.pdf

Falavarjani, M. F. \& Yeh, C. J. (2017). The impact of acculturation identification and acculturative stress on creativity among Iranian immigrants living in Malaysia. Journal of Ethnic and Migration Studies, 44(13), 2219-2239. http://dx.doi.org/10.1080/1369183X.2017.1366301

Fisher, S. \& Hood, B. M. (1987). The stress of the transition to university: A longitudinal study of psychological disturbance, absent-mindedness, and vulnerability to homesickness. British Journal of Psychology, 78(4), 425-441. http://dx.doi.org/10.1111/j.2044-8295.1987.tb02260.x

Gudykunst, W. B. (2006). Anxiety/uncertainty management theory. In E. Griffin (Ed.), A first look at communication theory, 426-438. Boston, MA: McGraw-Hill.

Gui, Y., Safdar, S. \& Berry, J. (2016). Mutual intercultural relations among university students in Canada. Frontiers: The Interdisciplinary Journal of Study Abroad, XXVII, 17-32.

Hagger, M. S., Hardcastle, S. J., Chater, A., Mallett, C., Pal, S. \& Chatzisarantis, N. L. (2014). Autonomous and controlled motivational regulations for multiple health-related behaviors: Between- and within-participants analyses. Health Psychology and Behavioral Medicine, 2(1), 565-601. https://doi.org/10.1080/21642850.2014.912945

Haghighat, Gh. (2016). Socio-cultural attitudes to ta'arof among Iranian immigrants in Canada. (Master's thesis). University of Saskatchewan, Saskatoon. Retrieved from https://ecommons.usask.ca/bitstream/handle/10388/ETD-2016-03-2487/HAGHIGHAT THESIS.pdf? sequence $=4 \&$ isAllowed $=\mathrm{y}$

Hartshorne, R. \& Baucom, J. (2007). Issues affecting cross-cultural adaptation of international graduate students. Multicultural Learning and Teaching, 2(2), 78-87. https://doi.org/10.2202/2161-2412.1023

Javidan, M. \& Dastmalchian, A. (2003). Culture and leadership in Iran: The land of individual achievers, strong family ties, and powerful elite. Academy of Management Executive, 17(4), 127-142. https://doi.org/10.5465/ame.2003.11851896

Kagitcibasi, C. (2002). A model of family change in cultural context. Online Readings in Psychology and Culture, 6(3). https://doi.org/10.9707/2307-0919.1059

Kagitcibasi, C. (2003). Autonomy, embeddedness and adaptability in immigration contexts. Human Development, 46 (2-3), 145-150. http://dx.doi.org/10.1159/000068584

Kagitcibasi, C. (2005). Autonomy and relatedness in cultural context. Journal of Cross-Cultural Psychology, 36(4), 403-422. http://dx.doi.org/10.1177/0022022105275959

Kagitcibasi, C. (2007). Family, self, and human development across cultures: Theory and applications (2nd ed.). Mahwah: Lawrence Erlbaum.

Kagitcibasi, C. (2013). Adolescent autonomy-relatedness and the family in cultural context: What is optimal? Journal of Research on Adolescence, 23(2), 223-235. http://dx.doi.org/10.1111/jora.12041

Kagitcibasi, C. (2016). From diversity to systematic patterns and integrative syntheses: A Journal in Cross-Cultural Psychology. In C. Roland-Lévy, P. Denoux, B. Voyer, P. Boski., W. K. Gabrenya Jr., Rhode, A.K. \& Lemoine, J. (Eds.), Unity, diversity, and culture: Research and scholarship selected from the 22nd congress of the international association for cross-cultural psychology, 59-62. Reims, France: International association for cross-cultural psychology. Retrieved from https://scholarworks.gvsu.edu/iaccp_papers/234/

Kunovski, M. \& Novoselova, N. (2018). Iranian students In Russian universities: Adaptation to the academic environment. EDULEARN18 Proceedings, 10667-10670. https://doi.org/10.21125/edulearn.2018.2612

Markova, V. (2006). Socio-cultural and psychological features of adaptation among Asian foreign students in Archangelsk, Russia, and Umea, Sweden. (Master's thesis). Umea University. Retrieved from 
http://www.phmed.umu.se/digitalAssets/30/30037_2006-4-veronika-markova.pdf

Masgoret, A.-M. \& Ward, C. (2006). Culture learning approach to acculturation. In D. L. Sam \& J. W. Berry (Eds.), The Cambridge handbook of acculturation psychology, 58-77. New York, NY, US: Cambridge University Press. http://dx.doi.org/10.1017/CBO9780511489891.008

Mehdizadeh., N. \& Scott, G. (2005). Adjustment problems of Iranian international students in Scotland. International Education Journal, 6(4), 484-493.

Merdin-Uygur, E. \& Hesapci, O. (2018). Alone but together, autonomous but related: Self-construal effects on happiness in social experiences. Journal of Consumer Behaviour, 17(3), 313-325. https://doi.org/10.1002/cb.1713

Mortazavi, S. (2006). The Iranian family in a context of cultural diversity. In Georgas, J., Berry, J. W., Van de Vijver, F. J. R., Kagitcibasi, C. \& Poortinga, Y. H. (Eds.). (2006). Families across cultures: A 30-nation psychological study, 378-385. New York, NY, US: Cambridge University Press. https://doi.org/10.1017/CBO9780511489822.026

Nabavi, R. T. \& Bijandi, M. S. (2018). An Investigation of predictors of life satisfaction among overseas Iranian undergraduate students. Educational Process: International Journal, 7(1), 74-93. http://dx.doi.org/ 10.22521/edupij.2018.71.6

Nahidi, S., Blignault, I., Hayen, A. \& Razee, H. (2018). Psychological distress in Iranian international students at an Australian university. Journal of Immigrant and Minority Health, 20 (3), 651-657. Springer Nature. http://dx.doi.org/10.1007/s10903-017-0590-8

Oktatási Hivatal. (2017-2018). Retrieved from https://www.oktatas.hu/felsooktatas/kozerdeku_adatok/felsooktatasi_adatok_kozzetetele/felsooktatasi_statisztik ak

Organisation for Economic Co-operation and Development (OECD). (2014). Indicator C4: Who studies abroad and where?, in Education at a Glance 2014: OECD Indicators, OECD Publishing, Paris. http://dx.doi.org/10.1787/888933118656

Ranney, M. L., Meisel, Z. F., Choo, E. K., Garro, A. C., Sasson, C. \& Morrow Guthrie, K. (2015). Interview-based qualitative research in emergency care Part II: Data collection, analysis and results reporting. Academic Emergency Medicine, 22(9), 1103-1112. https://doi.org/10.1111/acem.12735

Rosenthal D.A., Russell J. \& Thomson G. (2008). The health and wellbeing of international students at an Australian university. Higher Education, 55(1), 51-67. https://doi.org/10.1007/s10734-006-9037-1

Scharp, K. M., Paxman, C. G. \& Thomas, L. J. (2016). "I want to go home": Homesickness experiences and social support-seeking practices. Environment and Behavior, 48 (9), 1175-1197. https://doi.org/10.1177/0013916515590475

Shahmohammadi, M. (2014). Depression and Homesickness among Iranian Students in University Malaya (Master's thesis). The University of Malaya, Kuala Lumpur, Malaysia. Retrieved from http://studentsrepo.um.edu.my/7262/1/Depression_and_homesickness_.pdf

Valizadeh, L., Zamanzadeh, V., Rassouli, M. \& Rahkar Farshi, M. (2018). Concerns of parents with or raising adolescent children: A qualitative study of Iranian families. Journal of Caring Sciences, 7(1), 27-33. https://doi.org/10.15171/jcs.2018.005

Van Tilburg, M. A., Vingerhoets, A. J. \& Van Heck, G. L. (1996). Homesickness: A review of the literature. Psychological Medicine, 26(5), 899-912. https://doi.org/10.1017/S0033291700035248

Vansteenkiste, M., Lens, W., Soenens, B. \& Luyckx, K. (2006). Autonomy and relatedness among Chinese sojourners and applicants: Conflictual or independent predictors of well-being and adjustment? Motivation and Emotion, 30(4), 273-282. http://dx.doi.org/10.1007/s11031-006-9041-x

Ward, C. \& Kennedy, A. (1999). The measurement of sociocultural adaptation. International Journal of Intercultural Relations, 23(4), 659-677. http://dx.doi.org/10.1016/S0147-1767(99)00014-0

Ward, C., Bochner, S. \& Furnham, A. (2001). The psychology of culture shock (2nd ed.). New York, NY, US: Routledge.

Watkins, D., Mortazavi, S. \& Trofimova, I. (2000). Independent and interdependent conceptions of self: An 
investigation of age, gender, and culture differences in importance and satisfaction ratings. Cross-Cultural Research: The Journal of Comparative Social Science, 34(2), 113-134. https://doi.org/10.1177/106939710003400202

Woolf, N. (2007). A little structure in your codes will make your research a lot easier. ATLAS.ti library. (pp.3). Retrieved from https://atlasti.com/wp-content/uploads/2014/05/Woolf_2007-03_12.pdf

Woolf, N. H. \& Silver, C. (2018). Qualitative analysis using ATLAS.ti: The five-level QDA method (1st ed.). New York, NY: Routledge. https://doi.org/10.4324/9781315181684-1

\section{Note}

Note 1. Some sample questions:

Why did you want to study abroad? Why Hungary?

How do you feel here in Hungary?

How do you adapt to the language?

Have you faced any daily life hassles?

Have you ever faced discrimination in Hungary?

How important is it to you to maintain Persian culture? 